\title{
EXAMINATION OF THE EYE WITH INFRA-RED RADIATION*
}

\author{
BY
}

\author{
A. J. OGG \\ Salisbury
}

\section{PhOtography WITH INFRA-RED FILM}

Dekking $(1933,1934)$ published several photographs of eyes with dense corneal opacities using infra-red film and radiation of a wave-length of about $10,000 \AA$.U. His photographs strikingly demonstrated how infra-red radiation could penetrate a dense corneal opacity, and clearly record the appearance of the iris and pupil, which were invisible by ordinary methods of observation and photography. Similar infra-red photographs were later published by Mann (1935) and Feldman (1936). Kugelberg (1934) attempted infra-red photography of the fundus, but failed because of the difficulty in obtaining contrast and detail.

\section{Photography AND Direct ObServation With The Infra-Red Image CONVERTER TUBE}

Zworykin and Morton (1936) described an indirect method of infra-red photography which involved the use of an infra-red image converter tube. This electronic device consists of an evacuated tube, at one end of which there is a cathode coated with caesium silver oxide upon which the image of an object illuminated with infra-red radiation is focused. When a high electronic potential difference is applied between the cathode and anode, electrons are emitted from the cathode in proportion to the illumination at any point. The electron discharge on striking the anode at the other end of the tube, which is coated with a fluorescent material, produces a visible picture. This can either be viewed directly or photographed with a conventional film and camera (Fig. 1, opposite).

The infra-red image converter tube has the following advantages over infra-red film in the examination of the eye:

(1) It dispenses with the necessity for photography and infra-red film.

(2) The image can be focused directly on to the anode (with infra-red film the image is invisible and focusing must be calculated).

(3) Moving phenomena, such as pupillary activity and movements of the eye itself, may be directly observed in darkness without the aid of infra-red cinematography.

(4) The converter tube is sensitive to infra-red radiation of longer wave-length than infra-red film: such longer infra-red rays more readily penetrate opaque media.

* Received for publication May 14, 1957. 


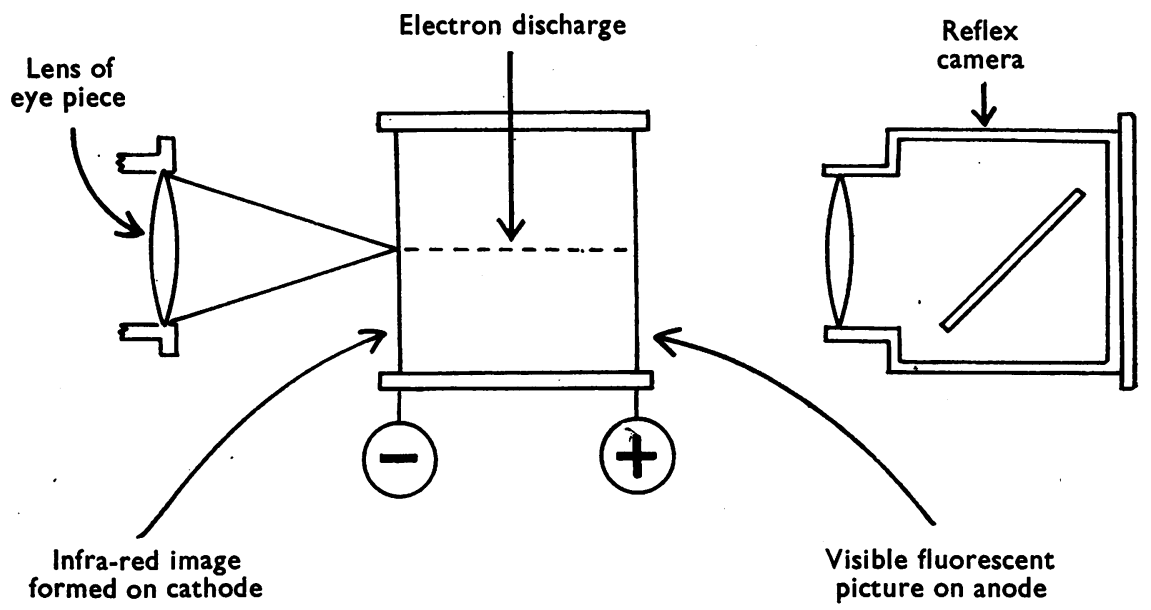

Fig. 1.-Electronic conversion of invisible infra-red radiation into a visible image.

Vaško and Peleška (1947) photographed the iris and pupil through an opaque cornea with a German army-type tube. Peleška (1951) described how fresh corneal infiltrates were more transparent than old opacities, how atrophied iris epithelium appeared black and could be mistaken for a coloboma, and how the opaque lens was more translucent than in normal light, but there was no possibility of examining a fundus through a cataract.

Kelly (1948) examined the anterior segment with the British army-type tube which was mounted on a slit lamp. He found the method of value in assessing the advisability of corneal grafting in certain cases. Marshall (1953), using a similar tube, observed eye movements away from fixation in rod scotometry. Knoll (1953) used the American tube for determining pupillary size and the refraction of the eye at low levels of illumination. Chin and Horn (1956) used an infra-red image converter tube to measure changes of refraction in dim illumination and in darkness.

\section{Comparison of Infra-Red Image Converter Tubes nOw Available}

The value of an examination of the anterior segment of an eye with a completely opaque cornea before corneal grafting and the appearance of pigment lesions when viewed by infra-red radiation stimulated the author to compare the various types of infra-red image converter cells at present available. It was not possible to obtain a suitable instrument from the manufacturers of electronic tubes in Great Britain, and the investigation was limited to the American "I.P.25", German "Vampire", and British "R.G." army-type tubes. Both the American and the German tubes are focused electromagnetically. The former gave a small bright image, but it was difficult to photograph. The latter produced a larger image, but unfortunately gunsight wires in the tube interfered with photography. Both are very difficult to obtain in Great Britain, and the American tube is very expensive. 
The British army-type has an immediate advantage over the others in that it is inexpensive and easily obtainable. It may be purchased from a number of stores dealing with ex-army electrical equipment and costs about fifteen shillings. It is of relatively simple construction, an inverted image being focused optically.

Use of the British Army-Type Tube.-The tube was mounted on the end of a beam attached to the top of the microscope of a Zeiss slit lamp in such a way that the cathode was facing and in line with the right eye-piece of the slit lamp. The beam was arranged to swing in an arc, so that the tube could easily be moved away to the right when an ordinary slit-lamp examination was undertaken (Fig. 2).

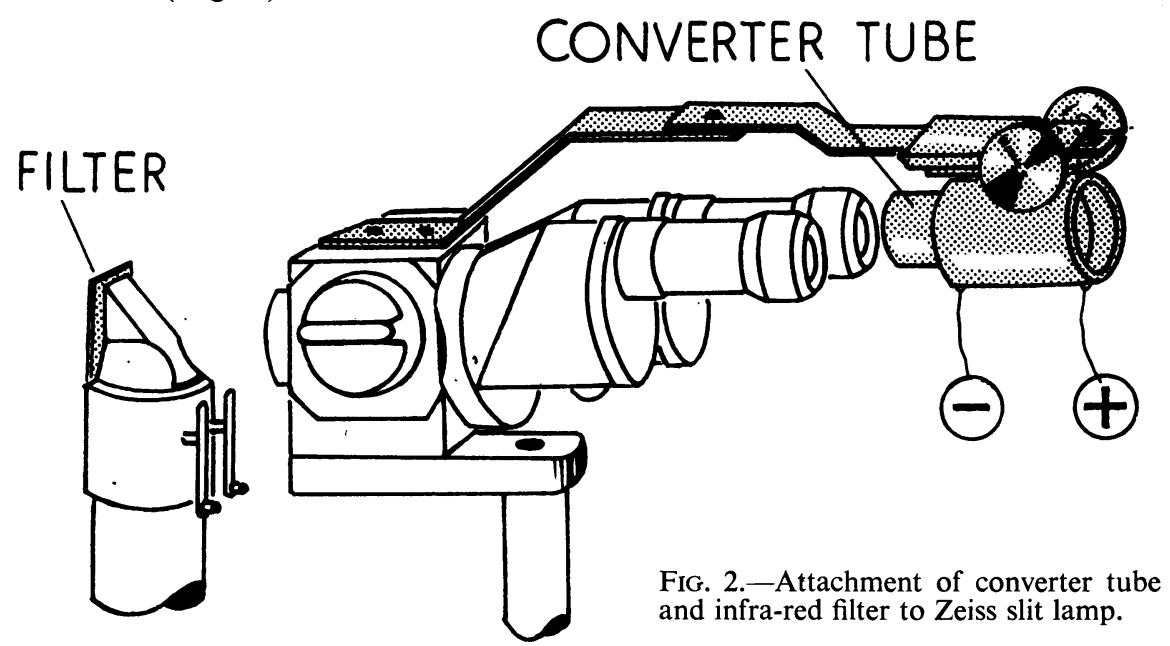

A source of infra-red radiation was produced by overloading the slit-lamp bulb filtered with an 87 "Wratten" filter. This was clipped on to the light source and could quickly and easily be removed. The tube was most efficient when operating at 8,000 volts. Fig. 3 (opposite) shows the circuit of the power unit employed.

Results obtained with the British Army-Type Tube.-For the patient the only sensation was one of slight warmth on the eye. For the examiner the use of the instrument was no more difficult than an ordinary slit-lamp examination. The image formed on the anode was sufficiently bright for a detailed examination to be made with ease. Photographs of the image on the anode were made with a single lens reflex camera (a reflex Korelle), but exposures of about one half of a second were required, even with fast film.

Fig. 4 (opposite) shows a normal partially dark-adapted eye photographed through the tube. The grid wires on the anode can be seen.

The only corneal lesion which proved to be completely opaque to infra-red radiation was calcareous degeneration. With the overloaded slit-lamp bulb 


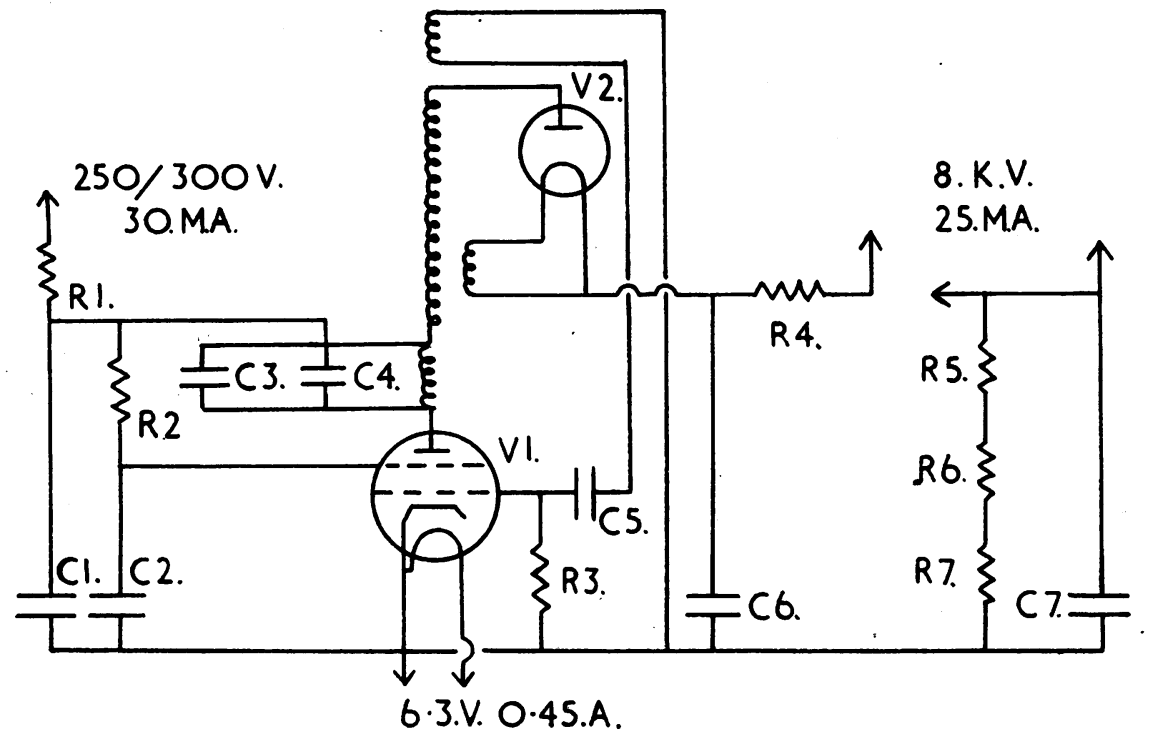

FIG. 3.-Circuit of power supply.

V.1. 6V.6.G.T

V.2. U.37.

R.1. $470 \frac{1}{2} \mathrm{~W}$.

R.2. $33 \mathrm{~K} . \frac{1}{2} \mathrm{~W}$.

R.3. $47 \mathrm{~K} . \frac{1}{2} \mathrm{~W}$.

R.4. $220 \mathrm{~K} \cdot \frac{1}{2} \mathrm{~W}$.

R.5., R.6., R.7., $33 \mathrm{~m}$. high voltage type. 
In the presence of a dense leucoma with partial calcareous degeneration, it was usually possible to estimate the depth of the anterior chamber by first bringing into focus the area of calcareous degeneration on the anterior corneal surface, and then focusing forwards on to the pupillary margin. It was not possible to form any accurate estimation of the corneal thickness. The size of the pupil and its shape and consensual reaction could be observed, but very little of the actual iris structure could be seen clearly.

Except for hypermature cataracts with calcareous degeneration, a lens opacity appeared quite transparent to infra-red, but it was never possible to see any normal retinal detail through a cataract. However, in one case of malignant melanoma of the choroid in an eye with a clear lens, observed through the converter tube, the tumour stood out black while the secondary retinal detachment was completely transparent. In this case transillumination with visible light showed a solid mass, but it is suggested that, in a case of suspected melanoma in an eye with a cataract, infra-red examination might be helpful when the result of transillumination is in doubt.

\section{Summary}

The earlier work with infra-red film is reviewed. The advantages of the infra-red image converter tube over infra-red photography in the examination of the anterior segment in the presence of a corneal opacity are described. The various types of converter tube are compared and the advantages of the British army-type tube discussed. Such a tube, mounted on a slit lamp, is of value in assessing the state of the pupil and the depth of the anterior chamber before corneal grafting. The tube may also prove to be useful in diagnosing choroidal melanoma in an eye with a cataract, which prevents conventional observation of the fundus and in which transillumination with visible light gives equivocal results.

I should like to thank Mr. E. F. Fincham for his help and advice, Dr. P. Hansell and his staff for preparing the illustrations, Dr. H. J. A. Dartnall for lending an American converter tube, and Dr. R. Barer for lending a German model.

\section{REFERENCES}

CHIN, N.B., and HoRn, R.E. (1956). J. opt. Soc. Amer., 46, 60.

DeKKING, H. M. (1933). v. Graefes Arch. Ophthal., 130, 373. (1934). Ibid., 133, 20.

Feldman, J. B. (1936). Arch. Ophthal. (Chicago), 15, 435.

Kelly, T. StuarT-Black (1948). Brit. J. Ophthal., 32, 396.

KNOLL, H. A. (1953). Amer. J. Optom., 30, 346.

KUGELBERG, I. (1934). Acta ophthal. (Kbh.), 12, 179.

MANN, W. A. (1935). Arch. Ophthal. (Chicago), 13, 985.

Marshall, M. F. P. (1935). Brit. J. Ophthal., 37, 316.

PelešKa, M. (1951). Čsl. ofthal., 7, 329.

PRATT, T. H. (1947). J. sci. Instrum., 24, 312.

VAŠKo, A., and PeleŠKA, M. (1947). Ibid., 31, 419.

ZWORYKIN, V. K., and MORTON, G. A. (1936). Electronics, 9, 10. 